\title{
Morphological analysis of Apolipoprotein E binding to $A \beta$ Amyloid using a combination of Surface Plasmon Resonance, Immunogold Labeling and Scanning Electron Microscopy
}

\author{
Tohidul Islam, Anna L. Gharibyan', Cheng Choo Lee ${ }^{2}$ and Anders Olofsson ${ }^{1 *}$ (i)
}

\begin{abstract}
Background: Immunogold labeling in combination with transmission electron microscopy analysis is a technique frequently used to correlate high-resolution morphology studies with detailed information regarding localization of specific antigens. Although powerful, the methodology has limitations and it is frequently difficult to acquire a stringent system where unspecific low-affinity interactions are removed prior to analysis.

Results: We here describe a combinatorial strategy where surface plasmon resonance and immunogold labeling are used followed by a direct analysis of the sensor-chip surface by scanning electron microscopy. Using this approach, we have probed the interaction between amyloid- $\beta$ fibrils, associated to Alzheimer's disease, and apolipoprotein $E$, a well-known ligand frequently found co-deposited to the fibrillar form of A $\beta$ in vivo. The results display a lateral binding of ApoE along the amyloid fibrils and illustrates how the gold-beads represent a good reporter of the binding.

Conclusions: This approach exposes a technique with generic features which enables both a quantitative and a morphological evaluation of a ligand-receptor based system. The methodology mediates an advantage compared to traditional immunogold labeling since all washing steps can be monitored and where a high stringency can be maintained throughout the experiment.
\end{abstract}

Keywords: Aß, ApoE, Immunogold, Surface plasmon resonance, SPR, Scanning electron microscopy, SEM, Fibrils, Morphology, Abeta

\section{Background}

Fibrillar aggregates of the amyloid $\beta$ peptide $(A \beta)$ are considered as one of the hallmarks of $\mathrm{AD}$ and their ultrastructural morphology and properties have been extensively studied. The $A \beta$-fibrils are represented by a $\beta$ sheet polymer where the lateral assembly of several thinner filaments constitute the final fibrillar morphology [1-3]. The formation of $A \beta$ amyloid fibrils follows a nucleation-dependent path of aggregation. Here an

\footnotetext{
* Correspondence: anders.olofsson@umu.se

${ }^{1}$ Department of Medical Biochemistry and Biophysics, Umeå University,

SE-901 87 Umeå, Sweden

Full list of author information is available at the end of the article
}

initially formed assembly of peptides acts as a template (a nucleus) for the subsequent incorporation of monomers resulting in a highly ordered fibrillar morphology of indefinite length. Similar to the growth of a crystal, a repeating structure is propagated. Although a single fibril represents a highly ordered structure a morphological heterogeneity is frequently observed and several fibrillar forms can usually be identified within the same sample. Understanding the mechanistic details of $A \beta$ assemblies is of interest in the design of therapeutic interventions $[4,5]$. In vivo, the intrinsic properties of the $A \beta$ peptide to form an amyloid are suppressed by several factors including degradation by neprilysin [6] and

(C) The Author(s). 2019 Open Access This article is distributed under the terms of the Creative Commons Attribution 4.0 International License (http://creativecommons.org/licenses/by/4.0/), which permits unrestricted use, distribution, and 
insulin-degrading enzyme [7]. A few endogenous proteins have also been found to interfere with the process of $A \beta$ amyloid formation, including proteins containing a BRICHOS domain [8-10], transthyretin (TTR) [1115], clusterin [16], and ApoE [17-20]. ApoE is in this context of specific interest where the $\varepsilon 4$ allele today represents the strongest genetic linker to the development of late onset $\mathrm{AD}$ [21]. Identification of the mechanism of binding including a morphological evaluation of the binding pattern is therefore of interest.

Immunogold labeling in combination with electron microscopy represents a technique used for the ultrastructural investigation of biological samples. The methodology reports the binding of e.g. an antibody to its antigen or a ligand to its receptor by conjugation to a gold particle and hence facilitates detailed structural information of the ultrastructural morphology. Immunogold techniques are however frequently hampered by the ability to remove unspecific low-affinity binding and hence to obtain a high stringency of the system. Consequently, it is often difficult to discriminate between relevant binding and non-specific interactions.

Within the SPR technique, the sample for analysis is frequently attached to a surface via strong covalent bonds and the immobilized proteins can then be probed by potential interaction partners through injections into a continuous flow of the media. The methodology facilitates detailed monitoring of binding kinetics including $K_{D}$ determination [22]. It is hence easy to monitor the removal of unspecific low-affinity interactions and the stringency of the system.

An SPR experiment frequently involves the acquired kinetic data from an interaction between e.g. a receptor and its ligand and in most cases this covers the required needs. The SPR technique has however been extensively used regarding the monitoring of amyloid formation [23-26] where a fibrillar ultrastructure is formed. Since an SPR chip is coated with a gold-surface it is amenable for SEM analysis which facilitates a direct morphological analysis of the formed structure on the surface. Within this work, we have studied the interaction between $A \beta$ fibrils and ApoE where we, in addition, demonstrate how the technique of immunogold labeling can be combined to illustrate the binding pattern. Using this approach, the kinetics of the probed ligands, as well as the washing of each step to remove low and unspecific binding can be monitored prior to the morphological analysis.

\section{Results}

Amyloid formation of $A \beta_{1-40}$ monitored by Thioflavin $T$ (ThT) assay and TEM

$A \beta_{1-40}$ readily forms fibrils under stagnant solutions in PBS and the relative proportion of fibrillar material can be monitored by using the amyloid-specific probe ThT. Figure 1a illustrates the kinetics of conversion of monomeric $A \beta_{1-40}$ to a fibrillar form, where the initial lagphase is followed by a logarithmic phase of fibril assembly, and subsequently reaches a plateau, where most of the monomeric fraction is converted to mature fibrils. Figure $1 \mathrm{~b}$ illustrates a representative negative stain TEM image of the fibrils formed at the end of ThT kinetics wherein overall fibrillar morphology is developed.

\section{Surface Plasmon resonance}

To study the binding of $A p o E$ to $A \beta_{1-40}$ fibrils using both SPR and SEM a scheme of analysis to include all controls was employed. In total 2000 response units (RU) of $A \beta_{1-40}$ fibrils were immobilized and then probed with ApoE until saturation binding had been acquired implicating that most of the accessible sites have been occupied (Fig. 2a). The $K_{D}$ of the binding between fibrils and recombinant human ApoE4 is strong and was calculated here to be around $5 \mathrm{nM}$, which is in overall good

\section{A}

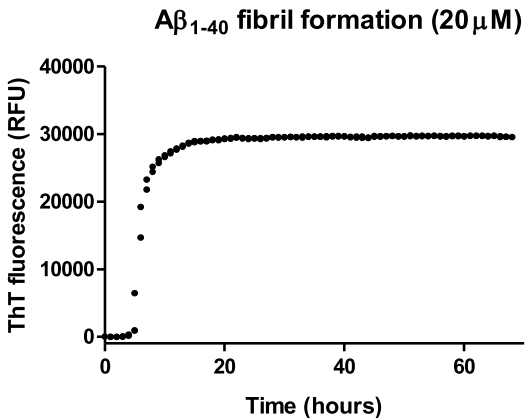

B

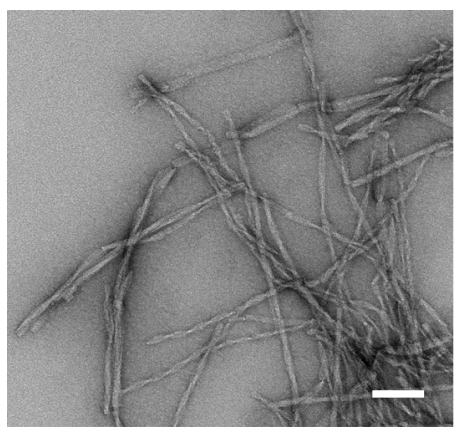

Fig. 1 ThT and TEM analysis of fibril formation of $A \beta_{1-40}$. a $20 \mu \mathrm{M}$ monomeric peptide solution of $A \beta_{1-40}$ was incubated in the presence of $40 \mu \mathrm{M}$ of the amyloid reporting probe ThT. A steady state of the plateau indicates that monomeric fraction has been consumed and converted to the fibrillar form. $\mathbf{b}$ Negative uranyl acetate staining of the $A \beta_{1-40}$ fibrils analyzed by TEM. Scale bar is $100 \mathrm{~nm}$ 


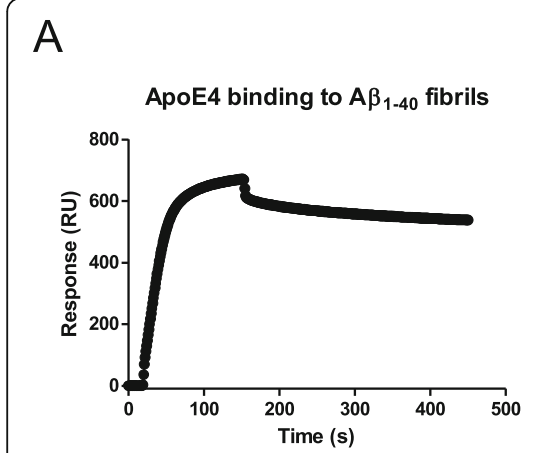

B

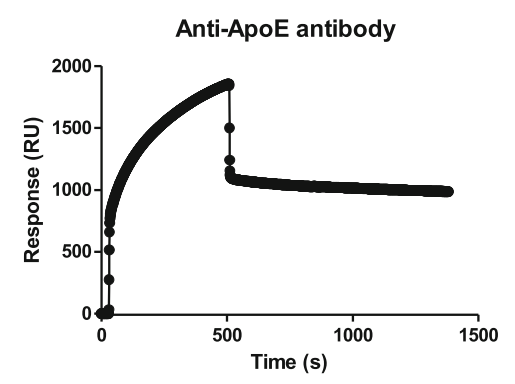

C

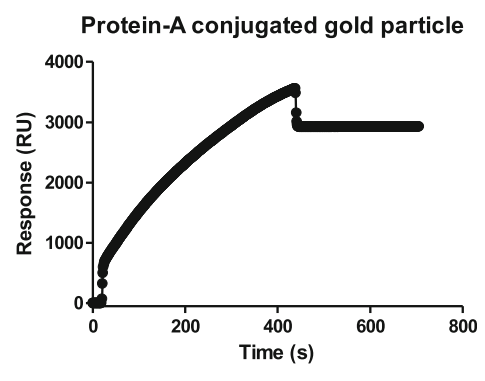

Fig. 2 SPR analysis facilitates sequential probing of ApoE, anti-ApoE antibody and protein-A conjugated gold-particle. SPR analysis of a ApoE4 binding to immobilized $A \beta_{1-40}$ fibrils, $\mathbf{b}$ ApoE4 bound $A \beta_{1-40}$ fibrils probed with anti-ApoE antibodies, and $\mathbf{c}$ Protein-A gold beads binding to the fibril-ApoE-antibody complex. The analysis was performed in degassed PBS at pH 7.4

agreement with previous investigations $[27,28]$. Bound ApoE4 was then probed through the addition of an antiApoE antibody, Fig. 2b. The removal of an excess of antibodies was effectively monitored using the SPR trace. As a last step $15 \mathrm{~nm}$ gold-beads conjugated to Protein-A was added and the binding monitored in analogy to previous steps, Fig. 2c.

\section{SEM-analysis of the CM5-chip surface}

Due to the conducting substrate (gold-surface of the CM5-chip) it is possible to make direct analysis by SEM. Ultra- small (diameters $<10 \mathrm{~nm}$ ), yet non-conducting materials such as the amyloid fibrils can be distinguished from the background by the inelastic electron scattering when the electron beam hits the sample surface at low accelerating voltage. The low-energy secondary electrons, detected by the in-lens detector, provide highresolution, surface-sensitive information, as well as compositional contrast, displaying darker shades of gray for the organic matter (fibrils) and brighter gray level for the heavier elements (gold beads). The gold-beads indirectly probing bound ApoE could be readily identified due to their strong electron scattering properties and therefore easily discriminated from the background of both the gold-surface of the CM5-chip and the immobilized fibrillar sample. Figure 3a indicates a control surface area where all components of the described system, apart from ApoE, has been added.

The results revealed a fibrillar morphology in accordance with the TEM analysis of the corresponding sample and in essence no background binding is anti-ApoE antibodies and the subsequently added protein- $\mathrm{A}$ coated gold-beads was observed. Figure $3 \mathrm{~b}$ shows the morphology of the sample after all components have been included. The results show how ApoE laterally decorates the amyloid fibrils, which is in accordance with previous
A

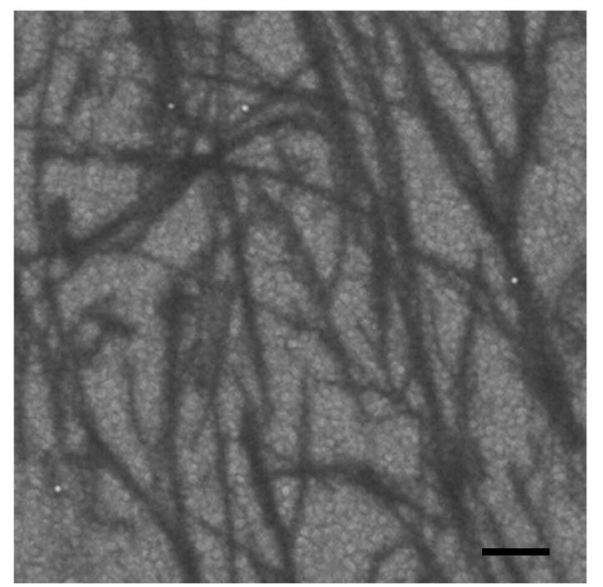

B

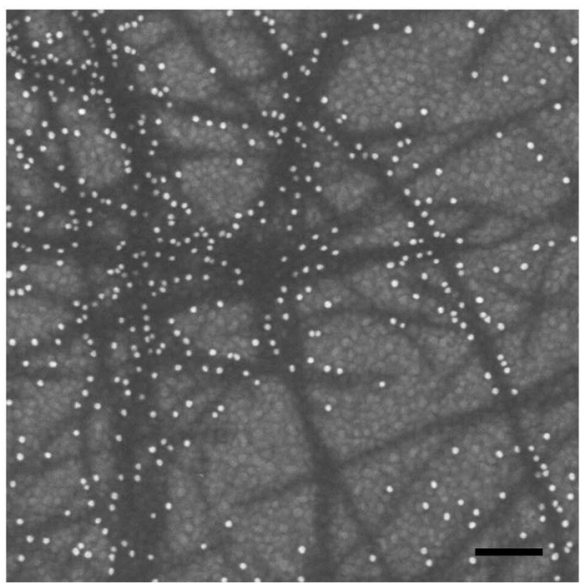

Fig. 3 SEM analysis of the SPR-chip surface. a Control sample in absence of added ApoE to probe for non-specific binding where the immobilized fibrils on the SPR-chip have been sequentially probed with anti-ApoE antibodies and protein-A conjugated $15 \mathrm{~nm}$ gold-beads. $\mathbf{b}$ Complete setup where fibrils bound to the SPR-chip have been sequentially probed with ApoE4, anti-ApoE antibodies and protein-A conjugated $15 \mathrm{~nm}$ gold-beads. Scale bar is $100 \mathrm{~nm}$ 
findings using traditional immunogold techniques in combination with TEM $[29,30]$. An apparent discrepancy can here be observed between different fibrils. While some fibrils are highly covered by the gold-beads others essentially completely lack any binding of ApoE, thus showing the absence of gold-beads. We observe the phenomenon of ApoE selectivity binding to certain fibrillar subtypes. However, due to the relatively low imaging resolution of SEM (compared to TEM) it is at this point of writing difficult to conclude if this is a technical artefact or if the observed results is based on a selectivity of ApoE for different types of fibrillar morphology.

\section{Discussion}

Gold-particles have been used within the field of electron microscopy for a very long time due to their remarkable electron density and are today available in different sizes and conjugated to different linker molecules [31, 32]. In the present study we described an alternative immunogold labeling approach by using a combination of SPR and SEM to achieve both quantitative and morphological evaluation of the sample.

A limiting factor regarding the traditional use of immunogold techniques is that the sample is not strongly immobilized onto the surface. This feature frequently hampers the removal of unspecific binding after probing with e.g. antibodies or ligands and it is as a consequence difficult to acquire a good signal to noise ratio since an appropriate washing is difficult to perform and monitor. Sample preparation for TEM is also frequently associated with negative staining using a water solution of uranyl-acetate having $\mathrm{pH}$ between 4 and 5 which also may compromise the binding and may cause dissociation of assembled protein complexes.

Present work is focused on the interaction between the amyloid form of $\mathrm{A} \beta$ and its well-known ligand $\mathrm{ApoE}$ where in particular the ApoE $\varepsilon 4$ allele is associated with a significantly increased risk of developing the disease [21, 33]. Through the current approach the fibrillar forms of the $A \beta$ peptide are covalently attached to the activated SPR surface of a CM5-chip. After immobilization the sample is washed by a continuous flow of PBS to acquire a steady baseline and a sample amenable for the probing with ligands according to standard procedures. Detection of bound ApoE was further performed by an anti-ApoE antibody followed by protein-A conjugated to $15 \mathrm{~nm}$ gold beads. Apart from the possibility to determine the binding affinities and kinetics of the binding the technique enables monitoring of all washing steps where e.g. low affinity interactions effectively can be removed.

The procedure in more general terms exposes a strategy that may be employed also in other contexts and serves as a versatile tool whenever the ultra-structural morphology is of interest in combination with binding kinetics.
Interestingly, we observed an unexpected discrepancy where ApoE frequently did not bind uniformly to all fibrils within a sample. While certain fibrils were highly covered with ApoE, others in essence completely lacked bound ApoE. While this may be a technical artefact an alternative option is that ApoE may have a selective affinity for certain fibrillar morphologies. Although a single fiber follows a very high structural order, similar to the formation of a crystal, fibrils may differ from each other and $A \beta$ samples frequently expose heterogeneous fibril morphology $[1-3,34]$. This can be easily observed by TEM and is also seen within the fibrillar samples used here (shown in Fig. 1b) where at least four different types of fibril morphologies can be identified. The discrepancy in binding (shown in the SEM images) may indicate that ApoE selectively attaches to certain fibrillar structures. While SEM is desirable for direct analysis of amyloid fibrils on SPR-chip, the strong background signals and non-featureless morphology of the gold-surface may prohibit detailed investigation of the fibrils. Future studies are therefore required to distinguish if this is a technical artefact or if ApoE may have a different selectivity for different fibrillar morphologies.

Taken together, we have demonstrated a combinatorial immunogold-labeling approach using SPR and SEM, which allows improving the stringency of the system of analysis. The setup facilitates both quantitative and morphological evaluation where importantly an efficient binding and washing can be monitored between each step in the sequential experimental approach defining the immunogold technique. The technique is in essence applicable to most setups using SPR where an ultrastructural morphology also is of interest. A schematic illustration of the setup is shown in Fig. 4.

\section{Methods}

Preparation of ApoE4 and $A \beta_{1-40}$ monomers

Recombinant lyophilized ApoE4, as well as recombinant lyophilized $A \beta_{1-40}$ peptides, were obtained from AlexoTech $A B$ (Umeå, Sweden). $A \beta_{1-40}$ was dissolved in 20 $\mathrm{mM} \mathrm{NaOH}$ while both ApoE was dissolved in PBS. To remove potential aggregates both $A p o E$ as well as $A \beta_{1-}$ 40 were subjected to size-exclusion chromatography (Superdex 75 10/300, GE Life Science, Uppsala, Sweden) in degassed PBS at $4{ }^{\circ} \mathrm{C}$ prior to its use. Both $\mathrm{A} \beta_{1-40}$ as well as ApoE eluted as a single peak.

\section{Preparation of $A \beta_{1-40}$ fibrils}

In order to prepare $A \beta_{1-40}$ fibrils, freshly gel-filtrated monomeric A $\beta$ in PBS was distributed in a 96-well microtiter plate with dark walls and clear bottom (Cat. No.3881, Corning, USA) to a final concentration of $20 \mu \mathrm{M}$ and incubated at $37^{\circ} \mathrm{C}$ in the presence of $40 \mu \mathrm{M}$ ThT. The aggregation process was monitored by 


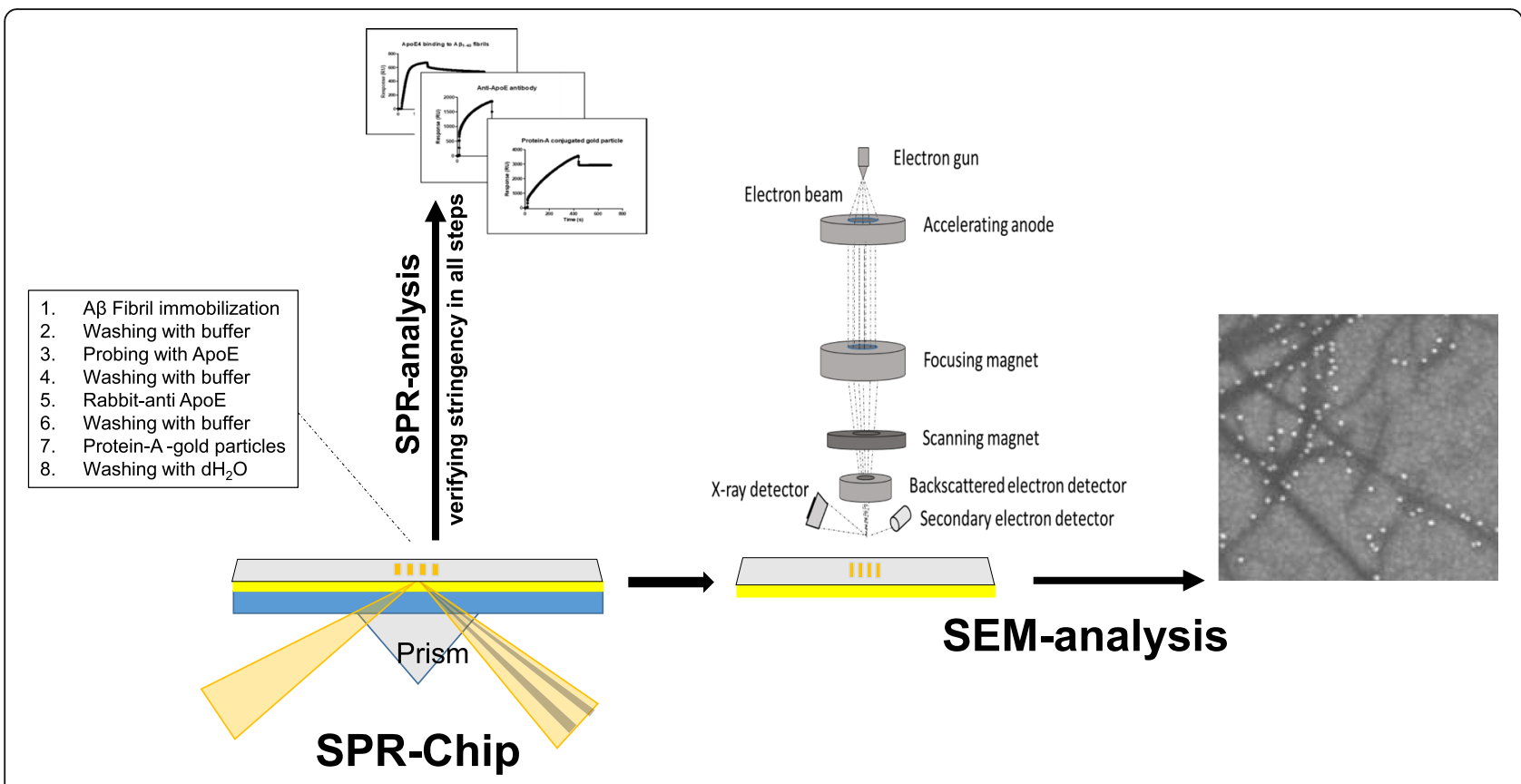

Fig. 4 Schematic illustration of the setup using immunogold staining in combination with SPR and SEM

recording the ThT signal using a fluorescence microplate reader (Tecan Infinite 200Pro, Männedorf, Switzerland) with excitation at $440 \mathrm{~nm}$ and emission at $480 \mathrm{~nm}$ according to standard procedures [35]. Fibrillar samples were considered ready when the binding of ThT reached a plateau.

Negative staining transmission electron microscopy (TEM) Prepared $A \beta_{1-40}$ fibrils were sonicated for $60 \mathrm{~s}$ in a water bath and a total volume of $3.5 \mu \mathrm{l}$ of fibrils was applied to 300 mesh formvar/carbon-coated, glow-discharged $\mathrm{Ni}$ grids. After $1.5 \mathrm{~min}$, the grid was washed in distilled water and consequently negatively stained for $15 \mathrm{~s}$ with $1.5 \%$ uranyl acetate (TAAB, Berks, England). Finally, fibrils were examined under a Talos L120 TEM (FEI) microscope $(120 \mathrm{kV})$ equipped with a Ceta CMOS $4 \mathrm{k} \times$ $4 \mathrm{k}$ pixel (FEI) camera supported with the FEI TIA (TEM imaging and analysis).

\section{Surface plasmon resonance}

The interaction between $A \beta$ fibrils and ApoE was monitored using a BIAcore 3000 biosensor (GE Healthcare, Uppsala, Sweden) equipped with a CM5 sensor chip (GE Healthcare). Prior to fibril immobilization the dextran matrix on the sensor chip surface was activated with a mixture of 1-ethyl-3- (3-dimethylaminopropyl) carbodiamide (EDC) and N-hydroxysuccinimide (NHS). A $\beta$ fibrils were immobilized at a density of 2000 response unit (RU) using standard amino coupling reagents and then deactivated according to the manufacture instruction. All SPR experiments were performed in degassed $\mathrm{PBS}$ at $25^{\circ} \mathrm{C}$.
Fibrils were immobilized at a flow rate of $5 \mu \mathrm{L} / \mathrm{min}$, whereas $\mathrm{A} \beta_{1-40}$ monomeric peptide solution, ApoE4, Anti-ApoE (rabbit polyclonal, Cat\# PA5-27088, ThermoFisher Scientific) and $15 \mathrm{~nm}$ protein-A gold beads (CMC Utrecht, Netherlands) were injected at a flow rate of $20 \mu \mathrm{L} / \mathrm{min}$. All the steps were followed by a $5 \mathrm{~min}$ flow of buffer, and after the final step additionally washed by degassed distilled water for $5 \mathrm{~min}$ at a flow rate of $50 \mu \mathrm{L} /$ min. Biosensor data were processed by BioLogic Software Scrubber2 and sensograms were made using GraphPad Prism 5.01.

\section{Scanning electron microscopy (SEM)}

Prior to analysis the SPR chip was disassembled and mounted onto an aluminium stub using carbon adhesive tape and a copper tape is applied between the chip surface and metal stub for proper electrical grounding. The sample morphology was examined by field-emission scanning electron microscope (FESEM; Carl Zeiss Merlin $\mathrm{GmbH}$ ) using an in-lens secondary electron (SE) detector at an accelerating voltage of $3 \mathrm{kV}$ and probe current of $90 \mathrm{pA}$. The immobilized and Au-labelled fibrils can be directly visualized at low beam accelerating voltage without the application of a thin metal coating. Furthermore, no additional steps of sample processing are required e.g. fixation, dehydration and drying.

\section{Abbreviations}

AD: Alzheimer's disease; ApoE: Apolipoprotein E; AB: Amyloid $\beta$ peptide; $K_{D}$ : Dissociation constant; RU: Response units; SEM: Scanning electron microscopy; SPR: Surface plasmon resonance; TEM: Transmission electron microscopy; ThT: Thioflavin T; TTR: Transthyretin 


\section{Acknowledgements}

Linnéa Olofsson for critically reviewing the manuscript.

\section{Authors' contributions}

$\mathrm{TI}$ and $\mathrm{CCL}$ performed the experiments. AO, TI, ALG and CCL conceived the idea and wrote the manuscript.

\section{Funding}

This work was supported by the National Microscopy Infrastructure, NMI (NR-RFI 2016-00968) at the Umeå Core Facility for Electron Microscopy, Demensförbundet, Insamlingsstiftelsen at Umeå University, Åhlén-stiftelsen, Hjärnfonden, FAMYNorrbotten, Olle Engkvist stiftelse (199-0469) and the Medical Faculty of Umeå University. The funders have no role in the design of the study, data collection or interpretation of data. Open access funding provided by Umea University.

\section{Ethics approval and consent to participate}

Not applicable.

\section{Availability of data and material}

Not applicable.

\section{Consent for publication}

Not applicable.

\section{Competing interests}

The authors declare that they have no competing interests.

\section{Author details}

'Department of Medical Biochemistry and Biophysics, Umeå University, SE-901 87 Umeå, Sweden. ${ }^{2}$ Umeå Core Facility for Electron Microscopy (UCEM), Umeå University, SE-90187 Umeå, Sweden.

\section{Received: 13 July 2019 Accepted: 27 November 2019}

\section{Published online: 11 December 2019}

\section{References}

1. Fandrich M, Meinhardt J, Grigorieff N. Structural polymorphism of Alzheimer Abeta and other amyloid fibrils. Prion. 2009;3(2):89-93.

2. Meinhardt J, Sachse C, Hortschansky P, Grigorieff N, Fandrich M. Abeta(1-40) fibril polymorphism implies diverse interaction patterns in amyloid fibrils. J Mol Biol. 2009;386(3):869-77.

3. Paravastu AK, Leapman RD, Yau WM, Tycko R. Molecular structural basis for polymorphism in Alzheimer's beta-amyloid fibrils. Proc Natl Acad Sci USA. 2008:105(47):18349-54.

4. Herling TW, Levin A, Saar KL, Dobson CM, Knowles TPJ. Microfluidic approaches for probing amyloid assembly and behaviour. Lab Chip. 2018; 18(7):999-1016.

5. Meisl G, Michaels TCT, Linse S, Knowles TPJ. Kinetic analysis of amyloid formation. Methods Mol Biol. 2018;1779:181-96.

6. Iwata N, Tsubuki S, Takaki Y, Watanabe K, Sekiguchi M, Hosoki E, KawashimaMorishima M, Lee HJ, Hama E, Sekine-Aizawa Y, et al. Identification of the major Abeta 1-42-degrading catabolic pathway in brain parenchyma: suppression leads to biochemical and pathological deposition. Nat Med. 2000;6(2):143-50

7. Jiang $\mathrm{Q}$, Lee $\mathrm{CY}$, Mandrekar S, Wilkinson B, Cramer P, Zelcer N, Mann K, Lamb B, Willson TM, Collins JL, et al. ApoE promotes the proteolytic degradation of Abeta. Neuron. 2008;58(5):681-93.

8. Biverstal H, Dolfe L, Hermansson E, Leppert A, Reifenrath M, Winblad B, Presto J, Johansson J. Dissociation of a BRICHOS trimer into monomers leads to increased inhibitory effect on Abeta42 fibril formation. Biochim Biophys Acta. 2015;1854(8):835-43.

9. Buxbaum JN, Johansson J. Transthyretin and BRICHOS: the paradox of Amyloidogenic proteins with anti-Amyloidogenic activity for Abeta in the central nervous system. Front Neurosci. 2017;11:119.

10. Willander H, Presto J, Askarieh G, Biverstal H, Frohm B, Knight SD, Johansson $J$, Linse S. BRICHOS domains efficiently delay fibrillation of amyloid betapeptide. J Biol Chem. 2012;287(37):31608-17

11. Buxbaum JN, Ye Z, Reixach N, Friske L, Levy C, Das P, Golde T, Masliah E, Roberts AR, Bartfai T. Transthyretin protects Alzheimer's mice from the behavioral and biochemical effects of Abeta toxicity. Proc Natl Acad Sci USA. 2008;105(7):2681-6.
12. Cascella R, Conti S, Mannini B, Li X, Buxbaum JN, Tiribilli B, Chiti F, Cecchi C. Transthyretin suppresses the toxicity of oligomers formed by misfolded proteins in vitro. Biochim Biophys Acta. 2013;1832(12):2302-14.

13. Garai K, Posey AE, Li X, Buxbaum JN, Pappu RV. Inhibition of amyloid beta fibril formation by monomeric human transthyretin. Protein Sci. 2018:27(7):1252-61.

14. Mangrolia P, Yang DT, Murphy RM. Transthyretin variants with improved inhibition of beta-amyloid aggregation. Protein Eng Des Sel. 2016;29(6): 209-18.

15. Nilsson L, Pamren A, Islam T, Brannstrom K, Golchin SA, Pettersson N, lakovleva I, Sandblad L, Gharibyan AL, Olofsson A. Transthyretin interferes with Abeta amyloid formation by redirecting Oligomeric nuclei into nonamyloid aggregates. J Mol Biol. 2018;430(17):2722-33.

16. Hammad SM, Ranganathan S, Loukinova E, Twal WO, Argraves WS. Interaction of apolipoprotein J-amyloid beta-peptide complex with low density lipoprotein receptor-related protein-2/megalin. A mechanism to prevent pathological accumulation of amyloid beta-peptide. J Biol Chem. 1997;272(30):18644-9.

17. Cerf E, Gustot A, Goormaghtigh E, Ruysschaert JM, Raussens V. High ability of apolipoprotein E4 to stabilize amyloid-beta peptide oligomers, the pathological entities responsible for Alzheimer's disease. FASEB J. 2011:25(5):1585-95.

18. Hashimoto T, Serrano-Pozo A, Hori Y, Adams KW, Takeda S, Banerji AO, Mitani A, Joyner D, Thyssen DH, Bacskai BJ, et al. Apolipoprotein E, especially apolipoprotein E4, increases the oligomerization of amyloid beta peptide. J Neurosci. 2012;32(43):15181-92.

19. Ly S, Altman R, Petrlova J, Lin Y, Hilt S, Huser T, Laurence TA, Voss JC. Binding of apolipoprotein $\mathrm{E}$ inhibits the oligomer growth of amyloid-beta peptide in solution as determined by fluorescence cross-correlation spectroscopy. J Biol Chem. 2013;288(17):11628-35.

20. Ghosh S, Sil TB, Dolai S, Garai K. High-affinity multivalent interactions between apolipoprotein $\mathrm{E}$ and the oligomers of amyloid-beta. FEBS J. 2019; https://doi.org/10.1111/febs.14988.

21. Corder EH, Saunders AM, Strittmatter WJ, Schmechel DE, Gaskell PC, Small GW, Roses AD, Haines IL, Pericak-Vance MA. Gene dose of apolipoprotein E type 4 allele and the risk of Alzheimer's disease in late onset families. Science. 1993:261(5123):921-3.

22. Drescher DG, Selvakumar D, Drescher MJ. Analysis of protein interactions by surface Plasmon resonance. Adv Protein Chem Struct Biol. 2018:110:1-30.

23. Brannstrom K, Islam T, Gharibyan AL, lakovleva I, Nilsson L, Lee CC, Sandblad L, Pamren A, Olofsson A. The properties of amyloid-beta fibrils are determined by their path of formation. J Mol Biol. 2018;430(13):1940-9.

24. Brannstrom K, Islam T, Sandblad L, Olofsson A. The role of histidines in amyloid beta fibril assembly. FEBS Lett. 2017;591(8):1167-75.

25. Brannstrom K, Ohman A, Lindhagen-Persson M, Olofsson A. Ca(2+) enhances Abeta polymerization rate and fibrillar stability in a dynamic manner. Biochem J. 2013;450(1):189-97.

26. Brannstrom K, Ohman A, Olofsson A. Abeta peptide fibrillar architectures controlled by conformational constraints of the monomer. PLoS One. 2011; 6(9):e25157.

27. Yamauchi K, Tozuka M, Nakabayashi T, Sugano M, Hidaka H, Kondo Y, Katsuyama T. Higher avidity binding of apolipoprotein (E-All) complex than of apolipoprotein E monomer to beta-amyloid. J Neurosci Res. 1999;58(2):301-7.

28. Golabek AA, Soto C, Vogel T, Wisniewski T. The interaction between apolipoprotein $\mathrm{E}$ and Alzheimer's amyloid beta-peptide is dependent on beta-peptide conformation. J Biol Chem. 1996;271(18):10602-6.

29. Garai K, Verghese PB, Baban B, Holtzman DM, Frieden C. The binding of apolipoprotein $\mathrm{E}$ to oligomers and fibrils of amyloid-beta alters the kinetics of amyloid aggregation. Biochemistry. 2014;53(40):6323-31.

30. Sanan DA, Weisgraber KH, Russell SJ, Mahley RW, Huang D, Saunders A, Schmechel D, Wisniewski T, Frangione B, Roses AD, et al. Apolipoprotein E associates with beta amyloid peptide of Alzheimer's disease to form novel monofibrils. Isoform apoE4 associates more efficiently than apoE3. J Clin Invest. 1994;94(2):860-9.

31. Faulk WP, Taylor GM. An immunocolloid method for the electron microscope. Immunochemistry. 1971;8(11):1081-3.

32. Baschong W, Stierhof YD. Preparation, use, and enlargement of ultrasmall gold particles in immunoelectron microscopy. Microsc Res Tech. 1998:42(1):66-79.

33. Ma J, Yee A, Brewer HB Jr, Das S, Potter H. Amyloid-associated proteins alpha 1-antichymotrypsin and apolipoprotein $\mathrm{E}$ promote assembly of Alzheimer beta-protein into filaments. Nature. 1994;372(6501):92-4. 
34. Komatsu H, Feingold-Link E, Sharp KA, Rastogi T, Axelsen PH. Intrinsic linear heterogeneity of amyloid beta protein fibrils revealed by higher resolution mass-per-length determinations. J Biol Chem. 2010;285(53):41843-51.

35. Brannstrom K, Ohman A, Nilsson L, Pihl M, Sandblad L, Olofsson A. The Nterminal region of amyloid beta controls the aggregation rate and fibril stability at low pH through a gain of function mechanism. J Am Chem Soc. 2014;136(31):10956-64.

\section{Publisher's Note}

Springer Nature remains neutral with regard to jurisdictional claims in published maps and institutional affiliations.

Ready to submit your research? Choose BMC and benefit from:

- fast, convenient online submission

- thorough peer review by experienced researchers in your field

- rapid publication on acceptance

- support for research data, including large and complex data types

- gold Open Access which fosters wider collaboration and increased citations

- maximum visibility for your research: over $100 \mathrm{M}$ website views per year

At $B M C$, research is always in progress.

Learn more biomedcentral.com/submissions 